\title{
Preamputation evaluation of limb perfusion with laser Doppler imaging and transcutaneous gases
}

\author{
Stephen F. Figoni, PhD, RKT; ${ }^{1}$ Oscar U. Scremin, MD, PhD; ${ }^{2-3^{*}}$ Charles F. Kunkel, MD, MS; ${ }^{1,4}$ \\ Dorene Opava-Rutter, MD; ${ }^{1}$ Jessica Johnson, PT; $^{1}$ Eric D. Schmitter, MD; ${ }^{5-6}$ A. M. Erika Scremin, MD $^{1,4}$ \\ Departments of ${ }^{1}$ Physical Medicine and Rehabilitation and ${ }^{2}$ Research, Department of Veterans Affairs Greater Los \\ Angeles Healthcare System (VAGLAHS), Los Angeles, CA; Departments of ${ }^{3}$ Physiology and ${ }^{4}$ Medicine, David Geffen \\ School of Medicine at University of California at Los Angeles (UCLA), Los Angeles, CA; ${ }^{5}$ Department of Surgery, \\ VAGLAHS, Los Angeles, CA; ${ }^{6}$ Department of Surgery, David Geffen School of Medicine at UCLA, Los Angeles, CA
}

\begin{abstract}
We studied 31 subjects with severe leg ischemia and 29 age-matched nonischemic control subjects to compare preamputation assessments of leg ischemia using laser Doppler imaging (LDI), transcutaneous partial pressure of oxygen $\left(\mathrm{TcPO}_{2}\right)$, and transcutaneous partial pressure of carbon dioxide $\left(\mathrm{TcPCO}_{2}\right) . \mathrm{TcPO}_{2}$ and $\mathrm{TcPCO}_{2}$ were evaluated with Novametrix Medical Systems, Inc, monitors (Wallingford, Connecticut) and perfusion (flux) of skin topically heated to $44{ }^{\circ} \mathrm{C}$, and adjacent nonheated areas were evaluated with a Moor Laser Doppler Imager (Moor Instruments, Ltd; Devon, England). LDI flux of heated areas, its ratio to nonheated areas, and $\mathrm{TcPO}_{2}$ (not $\mathrm{TcPCO}_{2}$ ) were lower in ischemic subjects than in control subjects. LDI flux ratio performed better than $\mathrm{TcPO}_{2}$ in identifying ischemia, with fewer false positive and false negative results. Moreover, LDI flux of heated skin detected a proximal to a distal gradient of perfusion in ischemic subjects, while $\mathrm{TcPO}_{2}$ did not. LDI was superior to $\mathrm{TcPO}_{2}$ in discriminating correctly between ischemic and nonischemic skin. The results suggest that an LDI ratio below 5 indicates nonviable skin.
\end{abstract}

Key words: amputation, blood gas monitoring, ischemia, laser Doppler flowmetry, leg, oxygen, perfusion, peripheral vascular diseases, rehabilitation, transcutaneous.

\section{INTRODUCTION}

Ischemia caused by peripheral vascular disease (PVD), with or without diabetes mellitus, accounts for the majority of lower-limb amputations [1-2]. Each year, over 150,000 persons in hospitals nationwide undergo amputations because of PVD or diabetes [3]. Although the standard of practice in most institutions is to assess limb perfusion through physical examination and clinical judgment, development of quantitative measurements of perfusion remains a desirable objective because perfusion determines the degree and progression of the pathological process that can lead to amputation. Distal amputations usually improve functional rehabilitative outcomes with prostheses, but this principle must be weighed against the fact that amputation through adequately perfused tissue at a proximal level accelerates healing and prevents revisions

\footnotetext{
Abbreviations: ANOVA = analysis of variance, $\mathrm{LDI}=$ laser Doppler imaging, NIR $=$ near infrared, $\mathrm{PCO}_{2}=$ partial pressure of carbon dioxide, $\mathrm{PO}_{2}=$ partial pressure of oxygen, $\mathrm{PVD}=$ peripheral vascular disease, $\mathrm{ROC}=$ receiver operating characteristic, $\mathrm{ROI}$ = region of interest, $\mathrm{SD}=$ standard deviation, $\mathrm{SEM}=$ standard error of the mean, Tc $=$ transcutaneous, $\mathrm{TcPO}_{2}=\mathrm{Tc}$ partial pressure of oxygen, $\mathrm{TcPCO}_{2}=\mathrm{Tc}$ partial pressure of carbon dioxide, VA = Department of Veterans Affairs, VAGLAHS = VA Greater Los Angeles Healthcare System.

* Address all correspondence to Oscar U. Scremin, MD, PhD; VAGLAHS, 11301 Wilshire Blvd, Bldg 115, Rm 319, Los Angeles, CA 90073; 310-268-3895; fax: 310-268-4209. Email: oscremin@ucla.edu DOI: 10.1682/JRRD.2006.02.0014
} 
[4-5]. Thus, for one to establish the ideal amputation level, a perfusion-based methodology is needed that can accurately determine the boundaries between those tissues that cannot potentially heal and those that can heal uneventfully.

Because assessment of local perfusion in limb ischemia poses a significant challenge, a number of methodologies have been proposed. The TransAtlantic Inter-Society Consensus identified transcutaneous (Tc) partial pressure of oxygen $\left(\mathrm{TcPO}_{2}\right)$, radionuclide scans, laser Doppler, and capillary microscopy as useful adjuncts in assessing critical limb ischemia but provided diagnostic guidelines only for $\mathrm{TcPO}_{2}$ [6]. $\mathrm{TcPO}_{2}$ was originally designed to monitor blood gases in neonates [7], but local blood flow was soon found to be a limiting factor in achieving equilibrium between blood $\mathrm{PO}_{2}$ and skin $\mathrm{PO}_{2}$ measured with $\mathrm{TcPO}_{2}$ electrodes [8]. Later, clinicians used this phenomenon to estimate the degree of local perfusion deficit by measuring the level of skin $\mathrm{PO}_{2}$ reached after enhancing local blood flow by topical heating [9-10]. However, many factors can affect the $\mathrm{TcPO}_{2}$ measurements, including local edema [11], anatomical localization [8], thickness of the epidermal stratum corneum [12-13], and leg dependency [14].

Several studies have evaluated the usefulness of laser Doppler flowmetry with fiber-optic contact probes for assessing amputation level and wound healing [15]. When used with topical heating that maximizes local blood flow, laser Doppler flowmetry detects a blood flow deficit in subjects with severe PVD [16-17] and correlates more highly with clinical PVD severity than $\mathrm{TCPO}_{2}$ or ankle Doppler pressure [15]. However, laser Doppler flowmetry with fiber-optic contact probes can only monitor small fixed areas of tissue. Because of the large variability between adjacent portions of skin, this limitation may affect its accuracy in mapping regional blood perfusion deficits. In laser Doppler imaging (LDI), a computercontrolled mirror projects a laser light onto the skin in a raster pattern. A portion of the back-scattered laser light is detected and the product of red cell velocity (calculated from the Doppler shift of the back-scattered light) and number of reflections is referred to as "flux" and used as a reliable index of tissue blood perfusion [18]. Thus, LDI is not limited to a single point and can scan large areas of skin, without direct contact, in a relatively short time [19].

The spatial and temporal reproducibility of LDI has been found to be higher than the single-probe laser Doppler method [20]. Kubli et al. have reported coeffi- cients of variation for LDI between 10 and 20 percent in response to iontophoretic drug administration [21], which indicates good day-to-day reproducibility. Therefore, LDI is potentially useful for the regional assessment of skin blood flow in PVD studies. However, normal perfusion values for this technique have not yet been established in the lower limbs and a systematic comparison with $\mathrm{TcPO}_{2}$ has not been described.

This study compares the accuracy of LDI and Tc gases in identifying ischemia in the legs of patients with severe PVD. In connection with this goal, the most clinically significant hypotheses were (1) LDI flux and Tc gases would differ significantly between the ischemic and control groups and (2) both methodologies would detect a proximal-to-distal decreasing gradient of perfusion in legs of subjects in the ischemic group and thus help determine the correct level for an amputation. Other questions were related to the degree of correlation between LDI and Tc gas measurements, their relative sensitivity and specificity, and the possible differences between LDI measurements with red and near-infrared (NIR) lasers.

\section{METHODS}

\section{Subjects}

We recruited 31 adult males from a convenience sample of patients for whom a transtibial amputation was imminent or scheduled because of lower-limb ischemia. In addition, 29 adult male nonischemic control subjects who were matched for age to the ischemic patients were also recruited.

\section{Inclusion and Exclusion Criteria for Ischemic Patients}

Adult patients who were identified as prospective candidates for unilateral transtibial amputation were recruited for the study if they met the following inclusion criteria: medically stable, without contractures of the lower limbs, able to perform a sit-to-stand transfer, and ambulatory within the previous 6 months. Exclusion criteria included dementia (Mini-Mental State Examination score $<24$ ) or inability to give informed consent, severe congestive heart failure, severe chronic obstructive pulmonary disease, terminal cancer with $<6$ months survival time, and severe limb weakness or ischemic pain preventing leg exercise. Patients were recruited from outpatient and inpatient programs of the Department of Veterans Affairs (VA) Greater Los Angeles Healthcare System (VAGLAHS). 


\section{Exclusion Criteria for Control Subjects}

Exclusion criteria for control subjects were diabetes mellitus, hypertension, history of foot pain while at rest or leg pain during ambulation or exercise, lower-limb bypass surgery, absence of anterior or posterior tibial pulses, abnormal skin pressure/skin refill test ( $>2 \mathrm{~s}$ ), smoking or drug use within the previous 6 months, dementia, and inability to plantar flex or dorsiflex ankles.

The VAGLAHS Institutional Review Board approved the study, and written informed consent was obtained from each subject before participation in this study.

\section{Instrumentation and Procedures}

\section{Measurement of $\mathrm{TcPO}_{2}$ and $\mathrm{TcPCO}_{2}$}

Five Tc gas monitors (model 860, Novametrix Medical Systems, Inc; Wallingford, Connecticut) equipped with combination $\mathrm{TcPO}_{2}$ and Tc partial pressure of carbon dioxide $\left(\mathrm{TcPCO}_{2}\right)$ probes with a heating element were used. The probes were $19 \mathrm{~mm}$ in diameter and were applied to the skin (previously shaved and cleaned with alcohol) with a $7 \mathrm{~mm}$-wide adhesive tape, concentric and external to the probe border. Three probes were positioned on an imaginary line joining the fibular head and lateral malleolus at one-third (lateral proximal), one-half (lateral middle), and two-thirds (lateral distal) of the distance between those structures. Two other probes were positioned on a line lateral to the tibial crest and over the anterior surface of the tibialis anterior muscle at one-third (anterior proximal) and one-half (anterior middle) of the same distance (fibular head to the lateral malleolus). During the measurements, subjects were in the supine position. Measurements were recorded every 2 minutes until a steady state level of $\mathrm{TcPO}_{2}$ (no variation in $\mathrm{TcPO}_{2}$ values over two consecutive measurements) was obtained.

\section{Measurement of Tissue Perfusion with LDI Scanning}

We performed LDI scans of the anterior and lateral leg surface, including the indicated $\mathrm{TcPO}_{2}$ and $\mathrm{TcPCO}_{2}$ probe locations, with the probes in place and immediately following their removal using a Moor Laser Doppler Imager (Moor Instruments, Ltd; Devon, England) fitted with red (633 nm wavelength) and NIR (830 nm wavelength) laser beams. Each scan yielded two coregistered images: (1) a two-dimensional color-coded map of perfusion and (2) a black-and-white light-intensity image showing the location of the probes with heating elements. Polygonal regions of interest (ROIs) (greatest diameter =
$10 \mathrm{~mm}$ ) corresponding to the position of the heating elements were drawn within the outline of these probe images. We coregistered these ROIs to the perfusion image and used them to calculate the mean, standard deviation (SD), minimum, maximum, and median of all the picture elements composing the ROI image of each heated area. The ROIs were then displaced to three locations adjacent to the heated area to obtain the statistics of the nonheated areas. Initial skin temperatures (before probe was applied) and final skin temperatures (immediately after probe removal) were measured at each site with a handheld infrared thermometer.

\section{Data Analysis}

After equilibration, we recorded the final $\mathrm{TcPO}_{2}$ and $\mathrm{TcPCO}_{2}$ and calculated the group mean and standard error of the mean (SEM) for each subject group and skin site (heated and nonheated). In the case of LDI, we obtained the mean, SD, minimum, maximum, and median of all individual flux values within each ROI and then calculated mean and SEM of these variables for each group and site. Flux ratios were calculated as the mean flux in every heated ROI divided by the mean flux in the three adjacent nonheated ROIs.

We used factorial analyses of variance (ANOVAs) to determine main effects and interactions for skin site (lateral proximal, lateral middle, lateral distal, anterior proximal, and anterior middle), laser (red or NIR), and condition (ischemic or control). We then used TukeyKramer post hoc tests to determine differences among the five skin sites. A probability of 0.05 was used to determine statistical significance. This analysis was performed for all the variables just defined (mean, SD, minimum, maximum, and median of all individual flux values within the ROIs).

We performed linear regression analyses of $\mathrm{TcPO}_{2}$ between LDI flux and LDI heated and nonheated area ratios on pooled data from all skin sites of each subject group (ischemic or control) separately. We performed all statistical calculations just mentioned using the Number Cruncher Statistical System (NCSS) software (NCSS Inc; Kaysville, Utah).

Receiver operating characteristic (ROC) curves are used to compare the performance of a diagnostic test with a "gold standard" in detecting the presence of a given condition. When the diagnostic test is a continuous variable, the comparisons between test and standard are performed at various test cutoff values. "Sensitivity" is the 
ratio of those cases that the test correctly identifies as having the condition (true positives) over the total number of cases with the condition. "Specificity" is the ratio of those cases that the test correctly identifies as not having the condition (true negatives) over the total number of cases without the condition [22]. Obviously, both variables can range from 0 to 1 . In the present application, the condition is "ischemia" and the gold standard is the physical examination and clinical judgment of the surgeon who identified the prospective subject as a candidate for a transtibial amputation. In other words, in this context, ROC curves evaluate how close the proposed test results (LDI, $\mathrm{TcPO}_{2}$, or $\mathrm{TcPCO}_{2}$ ) are to the gold standard (physical examination and clinical judgment) in identifying ischemia. As sensitivity increases, specificity decreases. When sensitivity and specificity are plotted over a range of cutoff values, the optimal cutoff value of the proposed test can be found by a compromise between sensitivity and specificity. Many factors are considered in making such a decision. In this particular diagnostic situation, where an important consideration is to avoid diagnosing ischemia when no such condition exists, keeping specificity of the test at a high level is desirable.

In addition, ROC analyses (Rockit 0.9Beta by Charles E. Metz; Department of Radiology, University of Chicago, Chicago, Illinois) were performed for $\mathrm{TcPO}_{2}$ and LDI data. We determined sensitivity and specificity of both techniques in detecting areas judged to lack healing potential by preamputation clinical criteria.

\section{RESULTS}

The ages of the ischemic and control subjects were not significantly different (Table 1), ruling out age as a source of variation in the results reported. Initial and final skin temperatures at test sites did not show differences among sites or between groups. In contrast, the time required to achieve a steady state of $\mathrm{TcPO}_{2}$, as defined in the "Methods" section, was longer in the ischemic subjects than in control subjects (Table 1). In this case, ANOVA indicated significance for the group factor (ischemic or control) but not for the site factor. The lack of significant interaction between the two factors indicated that the difference in heating time between the populations was uniform across sites.

\section{Laser Doppler Imaging}

Initially, ANOVAs were performed for the LDI variables mean, SD, minimum, maximum, and median flux within ROIs of heated and nonheated areas, including site (five leg sites: lateral proximal, lateral middle, lateral distal, anterior proximal, and anterior middle), group (ischemic or control), and laser (red or NIR) factors. These analyses indicated statistical significance for the laser factor in the case of many variables in heated and nonheated areas. Thus, separate ANOVAs for all variables and the site and group factors were performed for each laser wavelength. The results are summarized in Figure 1 and Tables 2-4. In the case of red laser, statistically significant ANOVA F-ratios for the group factor were found for all the variables in heated areas as well as the ratio of heated/nonheated areas, but none for the variables in the nonheated areas. The site factor ANOVA Fratios were not statistically significant for any of the variables. Similar results were obtained for the group factor with the NIR laser, although significance was found for the variable heated/nonheated ratio for the site factor (Table 3). In this case, Tukey-Kramer tests indicated that anterior sites had lower ratios than the lateral proximal site.

\section{Comparisons Between Red and Near-Infrared Lasers}

We tested the significance of differences between flux measured with the red or NIR lasers using ANOVA for each subject group (ischemic and control) separately with

Table 1.

Mean \pm standard error of mean of ischemic $(n=31)$ and control $(n=29)$ subjects' ages, time to reach steady state of transcutaneous partial pressure of oxygen (heating time), and skin temperature before (initial temperature) and after (final temperature) probe removal.

\begin{tabular}{lcc}
\hline \multicolumn{1}{c}{ Variable } & Ischemic & Control \\
\hline Age $(\mathrm{yr})$ & $58.60 \pm 1.50$ & $61.10 \pm 2.28$ \\
Heating Time $(\mathrm{min})^{*}$ & $35.50 \pm 1.08$ & $28.90 \pm 0.78$ \\
Temperature $\left({ }^{\circ} \mathrm{C}\right)$ & & $31.30 \pm 0.07$ \\
$\quad$ Initial & $31.20 \pm 0.11$ & $37.20 \pm 0.18$ \\
$\quad$ Final & $37.50 \pm 0.16$ & \\
\hline
\end{tabular}

* Probability level of statistical test to compare ischemic and control subject groups is $p<0.001$. Tests for other variables were nonsignificant. 

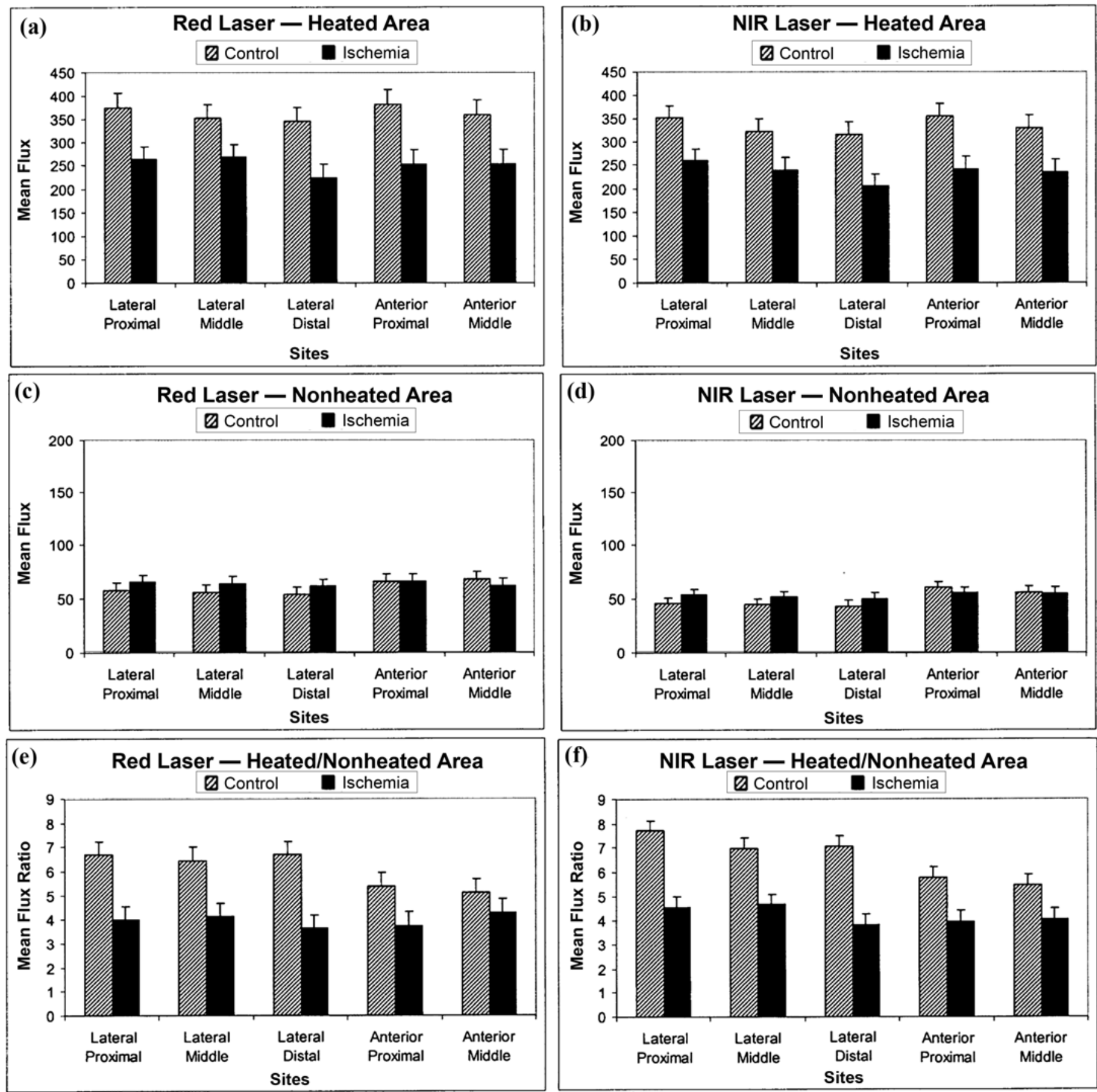

Figure 1.

Mean (bars) \pm standard error of mean (error bars) of flux in (a) and (b) heated areas and (c) and (d) nonheated areas and ratio of (e) and (f) heated to nonheated areas in control (cross-hatched bars) and ischemic subjects (solid bars). Data (a), (c), and (e) taken with red laser and (b), (d), and (f) near-infrared laser. For definition of sites, see "Methods" section, and for statistical significance, see Tables 3 and 4.

site and laser-type factors (Table 4). The results indicated that the mean ROI flux values from the NIR laser were smaller than with the red laser (Figure 1), although this trend was only statistically significant for the data of nonheated areas for LDI variables (Table 4). The variability (SD) of flux within the ROIs was significantly smaller 
Table 2.

Mean \pm standard error of mean standard deviation (SD), minimum (min), and maximum (max) flux of all flux values within each region of interest for different skin sites in heated and nonheated areas of control $(n=29)$ and ischemic $(n=31)$ subjects measured with red or near-infrared lasers. For definition of sites, see "Methods" section, and for statistical significance, see Tables $\mathbf{3}$ and 4.

\begin{tabular}{|c|c|c|c|c|c|c|}
\hline \multirow{2}{*}{ Sites } & \multicolumn{3}{|c|}{ Control } & \multicolumn{3}{|c|}{ Ischemic } \\
\hline & SD & Min & Max & SD & Min & Max \\
\hline \multicolumn{7}{|l|}{ Heated } \\
\hline Lateral Proximal & $139 \pm 14$ & $139 \pm 16$ & $800 \pm 68$ & $104 \pm 13$ & $102 \pm 19$ & $621 \pm 79$ \\
\hline Lateral Middle & $123 \pm 11$ & $138 \pm 16$ & $708 \pm 65$ & $102 \pm 9$ & $93 \pm 19$ & $587 \pm 58$ \\
\hline Lateral Distal & $122 \pm 10$ & $123 \pm 15$ & $700 \pm 57$ & $96 \pm 10$ & $75 \pm 18$ & $538 \pm 61$ \\
\hline Anterior Middle & $129 \pm 11$ & $138 \pm 18$ & $807 \pm 72$ & $121 \pm 26$ & $90 \pm 17$ & $756 \pm 67$ \\
\hline \multicolumn{7}{|l|}{ Near-Infrared Laser } \\
\hline Lateral Proximal & $103 \pm 7$ & $145 \pm 18$ & $636 \pm 42$ & $83 \pm 9$ & $103 \pm 17$ & $507 \pm 58$ \\
\hline Lateral Middle & $104 \pm 7$ & $130 \pm 13$ & $636 \pm 42$ & $74 \pm 7$ & $104 \pm 18$ & $462 \pm 47$ \\
\hline Lateral Distal & $104 \pm 7$ & $132 \pm 12$ & $613 \pm 38$ & $70 \pm 9$ & $83 \pm 17$ & $426 \pm 57$ \\
\hline \multicolumn{7}{|l|}{ Red Laser } \\
\hline Lateral Proximal & $35 \pm 4$ & $7 \pm 2$ & $192 \pm 28$ & $41 \pm 6$ & $9 \pm 3$ & $224 \pm 33$ \\
\hline Lateral Middle & $37 \pm 5$ & $6 \pm 1$ & $216 \pm 39$ & $41 \pm 5$ & $9 \pm 3$ & $237 \pm 38$ \\
\hline Lateral Distal & $36 \pm 4$ & $6 \pm 1$ & $209 \pm 35$ & $40 \pm 5$ & $8 \pm 3$ & $230 \pm 36$ \\
\hline Anterior Proximal & $41 \pm 8$ & $12 \pm 2$ & $276 \pm 71$ & $46 \pm 12$ & $10 \pm 3$ & $264 \pm 70$ \\
\hline Anterior Middle & $40 \pm 7$ & $12 \pm 2$ & $240 \pm 50$ & $48 \pm 10$ & $9 \pm 3$ & $230 \pm 50$ \\
\hline \multicolumn{7}{|l|}{ Near-Infrared Laser } \\
\hline Lateral Proximal & $23 \pm 1$ & $7 \pm 1$ & $135 \pm 15$ & $24 \pm 2$ & $9 \pm 3$ & $132 \pm 12$ \\
\hline Lateral Middle & $22 \pm 1$ & $7 \pm 1$ & $115 \pm 8$ & $23 \pm 2$ & $9 \pm 3$ & $132 \pm 12$ \\
\hline Lateral Distal & $21 \pm 1$ & $5 \pm 1$ & $113 \pm 7$ & $22 \pm 1$ & $9 \pm 3$ & $135 \pm 16$ \\
\hline
\end{tabular}

with the NIR laser for both subject groups in the heated areas, but only for control group in the nonheated areas (Tables 2-3). Maximum values within ROIs were significantly lower for the NIR laser in heated and nonheated areas for both groups. Ratios calculated from NIR laser data were higher than those from the red laser, but only for the control group (Figure 1 and Table 4).

Regarding differences in laser measurements depending on site, none of the ANOVA F-ratios for this factor was statistically significant in the ischemic group (Table 4). On the other hand, significant ANOVA F-ratios were found in nonheated areas of the control group for the following variables with significant differences between sites indicated between parentheses: ROI mean (anterior proximal > lateral distal), ROI median (anterior proximal and middle > lateral distal), ROI minimum (anterior proximal and middle > lateral proximal, middle, and distal), heated/nonheated ratio (lateral proximal, middle and distal > anterior middle; lateral proximal > anterior proximal).

\section{$\mathrm{TcPO}_{2}$ and $\mathrm{TcPCO}_{2}$}

Data on Tc gases obtained after equilibration are summarized in Figure 2. In the case of $\mathrm{TcPO}_{2}$, ANOVA indicated significance for the group factor $(F=52.02, p<$ $10^{-6}$ ) with ischemic subjects significantly lower than normal controls (Tukey-Kramer test, $p<0.05$ ). Marginal significance was found for the site factor $(F=2.44, p=$ $4.7 \times 10^{-2}$ ), although in this instance, multiple comparisons did not reach statistical significance between any pairs among the five sites. The interaction factor between sites and groups was not significant $(F=0.82, p=0.52)$, 
Table 3.

Main effects of analysis of variance (F-ratio) for skin site and group (ischemic [ $n=31]$ or control $[n=29]$ subjects) factors for laser Doppler imaging variables measured with red or near-infrared lasers.

\begin{tabular}{|c|c|c|c|c|}
\hline \multirow{2}{*}{ Variable } & \multicolumn{2}{|c|}{ Red Laser } & \multicolumn{2}{|c|}{ Near-Infrared Laser } \\
\hline & Site & Group & Site & Group \\
\hline \multicolumn{5}{|l|}{ Heated } \\
\hline Mean & 0.55 & $35.35^{*}$ & 0.98 & $37.98^{*}$ \\
\hline Standard Deviation & 0.48 & $8.54^{\dagger}$ & 0.29 & $40.24^{*}$ \\
\hline Minimum & 0.51 & $20.29^{*}$ & 0.60 & $17.23^{*}$ \\
\hline Maximum & 1.40 & $10.64^{\ddagger}$ & 0.46 & $32.67^{*}$ \\
\hline Median & 0.27 & $35.35^{*}$ & 0.81 & $24.61^{*}$ \\
\hline \multicolumn{5}{|l|}{ Nonheated } \\
\hline Mean & 0.70 & 1.26 & 2.26 & 0.33 \\
\hline Standard Deviation & 0.38 & 1.49 & 1.80 & 0.10 \\
\hline Minimum & 1.14 & 0.05 & 1.44 & 1.15 \\
\hline Maximum & 0.52 & 0.13 & 0.85 & 0.94 \\
\hline Median & 0.67 & 0.72 & 1.99 & 1.04 \\
\hline Heated/Nonheated (mean) & 1.31 & $58.48^{*}$ & $4.33^{\pi}$ & $88.1^{*}$ \\
\hline $\begin{array}{l}{ }^{*} p<0.001 \\
{ }^{\dagger} p=0.009 . \\
{ }^{\ddagger} p=0.001 . \\
{ }^{\dagger} p=0.002 .\end{array}$ & & & & \\
\hline
\end{tabular}

Table 4.

Main effects of analysis of variance for skin site and laser type (red or near-infrared) factors for laser Doppler imaging variables measured in ischemic or control subjects. Only significant $p$-values are given.

\begin{tabular}{|c|c|c|c|c|c|c|c|}
\hline \multirow{3}{*}{ Variable } & \multicolumn{3}{|c|}{ Ischemic } & \multicolumn{4}{|c|}{ Control } \\
\hline & \multicolumn{2}{|c|}{ Laser Type } & \multirow{2}{*}{$\begin{array}{c}\text { Site } \\
\text { F-Ratio }\end{array}$} & \multicolumn{2}{|c|}{ Laser Type } & \multicolumn{2}{|c|}{ Site } \\
\hline & F-Ratio & $p$-Value & & F-Ratio & $p$-Value & F-Ratio & $p$-Value \\
\hline \multicolumn{8}{|l|}{ Heated } \\
\hline Mean & 0.67 & - & 0.84 & 2.59 & - & 0.89 & - \\
\hline Standard Deviation & 18.24 & $<0.001$ & 0.40 & 15.14 & $<0.001$ & 0.54 & - \\
\hline Minimum & 1.10 & - & 0.66 & 0.05 & - & 0.64 & - \\
\hline Maximum & 10.72 & 0.001 & 0.80 & 14.90 & $<0.001$ & 2.07 & - \\
\hline Median & 0.04 & - & 0.82 & 1.54 & - & 0.71 & - \\
\hline \multicolumn{8}{|l|}{ Nonheated } \\
\hline Mean & 9.30 & 0.003 & 0.34 & 13.05 & $<0.001$ & 4.09 & 0.003 \\
\hline Standard Deviation & 2.57 & - & 1.15 & 28.82 & $<0.001$ & 0.58 & - \\
\hline Minimum & 0.53 & - & 0.47 & 0.02 & - & 6.91 & $<0.001$ \\
\hline Maximum & 23.83 & 0.002 & 0.19 & 21.48 & $<0.001$ & 0.75 & - \\
\hline Median & 2.62 & - & 0.50 & 7.24 & 0.008 & 3.80 & 0.005 \\
\hline Heated/Nonheated (mean) & 0.58 & - & 1.20 & 4.96 & 0.003 & 6.64 & $<0.001$ \\
\hline
\end{tabular}

which indicates that the difference between groups was uniform across sites. TcPCO 2 values did not show differences between sites or groups (site factor $F=1.02, p=$ 0.39 ; group factor $F=0.70, p=0.40$ ).

\section{Correlations Between LDI and $\mathrm{TcPO}_{2}$}

Linear regression analyses revealed a lack of correlation $\left(r^{2}\right)$ between $\mathrm{TcPO}_{2}$ and LDI flux of heated areas in the control group subjects and a statistically significant 

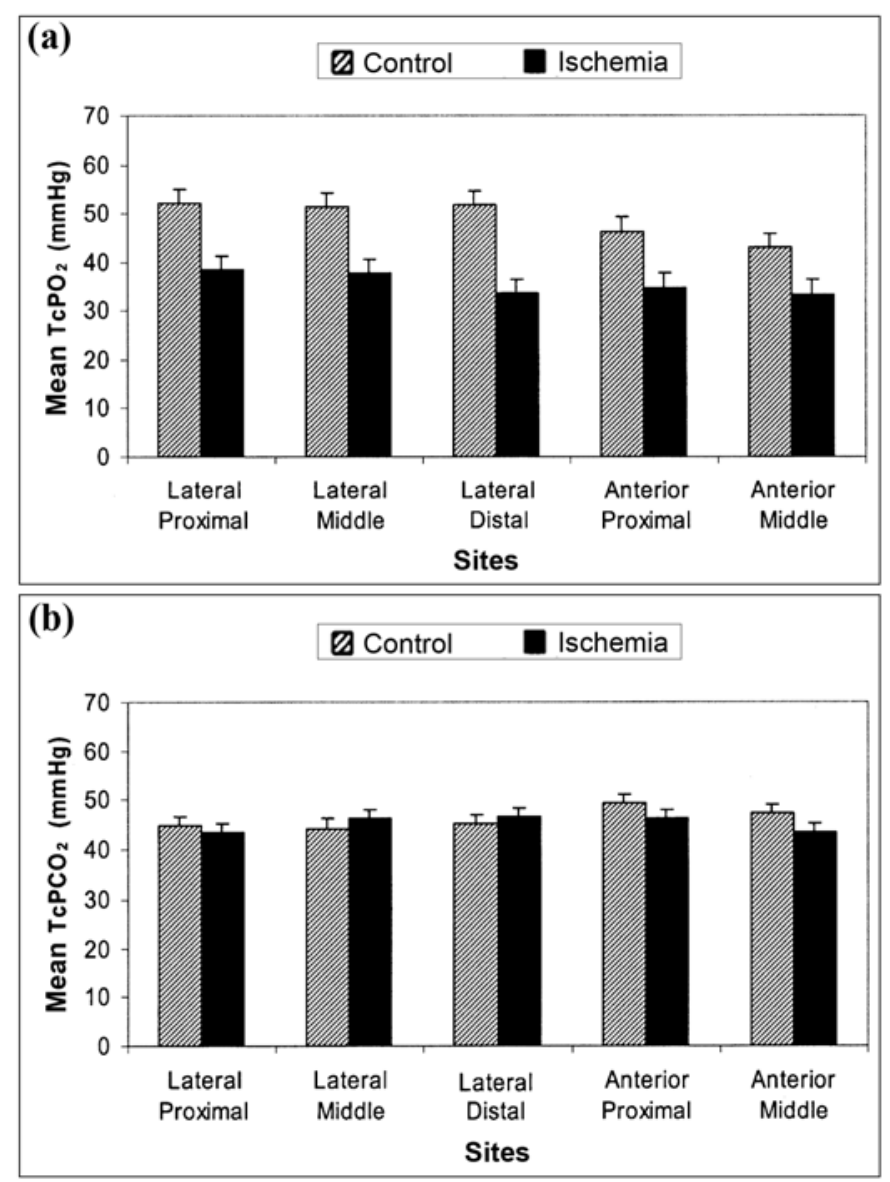

Figure 2.

Mean (bars) \pm standard error of mean (error bars) of (a) transcutaneous partial pressure of oxygen $\left(\mathrm{TcPO}_{2}\right)$ and (b) transcutaneous partial pressure of carbon dioxide $\left(\mathrm{TcPCO}_{2}\right)$ in control subjects (crosshatched bars) and ischemic subjects (solid bars). For $\mathrm{TcPO}_{2}$, analysis of variance indicated that ischemic subjects were significantly lower than control subjects $(F=52.02, p<0.001)$ and that this phenomena was uniform across sites (interaction factor between sites and groups not significant). No significant difference was found for $\mathrm{TCPCO}_{2}$ between groups.

but weak correlation in ischemic group subjects. The correlations between LDI and $\mathrm{TcPO}_{2}$ improved for the heated/nonheated areas ratio, but they remained at low $r^{2}$ values (Table 5).

\section{ROC Analysis}

We completed the ROC analysis to evaluate specificity and sensitivity of all variables. This analysis indicated a lack of positive or negative predictive value for fluxrelated variables of nonheated areas or $\mathrm{TCPCO}_{2}$, but significant predictive values for flux-related variables of heated areas (measured with either laser type) and
Table 5.

Results of linear regression analysis of transcutaneous partial pressure of oxygen on laser Doppler imaging variables for red and nearinfrared (NIR) lasers of ischemic $(n=31)$ and control $(n=29)$ subjects.

\begin{tabular}{lccccc}
\hline \multirow{2}{*}{ Variable } & \multicolumn{2}{c}{ Ischemic } & & \multicolumn{2}{c}{ Control } \\
\cline { 2 - 3 } \cline { 5 - 6 } & $\boldsymbol{r}^{\mathbf{2}}$ & Slope & & $\boldsymbol{r}^{\mathbf{2}}$ & Slope \\
\hline Red & 0.15 & $0.036^{*}$ & & 0.03 & -0.016 \\
$\quad$ Heated & & & & & \\
$\quad$ Heated/Nonheated & 0.19 & $2.093^{*}$ & & 0.12 & $1.988^{*}$ \\
NIR & & & & \\
$\quad$ Heated & 0.19 & $0.041^{*}$ & & 0.04 & 0.062 \\
$\quad$ Heated/Nonheated & 0.24 & $2.934^{*}$ & & -0.03 & $1.756^{*}$ \\
\hline
\end{tabular}

$\mathrm{TcPO}_{2}$. The NIR laser flux-related variables for which the areas under the ROC curves were significantly different from 0.5 (chance or complete lack of predictive value) are listed in Table 6, Although LDI flux ratio showed a greater area under the ROC curve than $\mathrm{TcPO}_{2}$, the difference was not statistically significant (correlated two-tailed $p$-value $=0.17$ ). However, contrasts between the true positive fraction (sensitivity) values for the two methods at specificities of 0.9 or better (abscissa in ROC plots $\leq 0.1$, Figure 3(a)) indicated significantly higher sensitivity for flux ratio at $p<0.05$. The sensitivity and specificity of NIR laser flux ratio and $\mathrm{TcPO}_{2}$ for different cutoff values are shown in Figure 3. This figure indicates that at a cutoff value of 5, the NIR LDI flux ratio maintains better than 0.9 specificity at a still acceptable level of $>0.7$ sensitivity (Figure $3(\mathbf{b})$ ). In contrast, at the same level of specificity, sensitivity for $\mathrm{TcPO}_{2}$ was only 0.4 , with a $30 \mathrm{mmHg}$ cutoff value (Figure 3(c)).

\section{Perfusion Gradient Within Leg}

The hypothesis that leg skin perfusion decreased from proximal to distal sites was tested in the ischemic group with LDI and $\mathrm{TcPO}_{2}$. To decrease the variance among subjects while preserving the differences among sites within subjects, we normalized LDI flux of heated areas and $\mathrm{TcPO}_{2}$ from lateral middle and distal sites by dividing by the lateral proximal site values in each subject. A significant proximal-to-distal gradient was detected with the red and NIR normalized flux (Figure 4). ANOVA indicated significance for the red laser LDI flux $(F=4.55, p=0.01)$ and the NIR laser LDI flux $(F=5.99$, $p=0.004$ ), and multiple comparisons (Tukey-Kramer test) showed that the distal LDI flux was significantly lower than middle and proximal sites with the red laser 
Table 6.

Areas under curve (AUC) of receiver operating characteristic plots and their 95\% confidence limits (CLs). Only variables with AUC significantly $>0.5$ are shown.

\begin{tabular}{lccc}
\multicolumn{1}{c}{ Variable } & AUC & 95\% Lower CL & 95\% Upper CL \\
\hline Heated/Nonheated Mean NIR Flux & 0.89 & 0.78 & 0.97 \\
TcPO $_{2}$ & 0.82 & 0.69 & 0.92 \\
NIR Flux, Heated & & 0.68 & 0.91 \\
$\quad$ Standard Deviation & 0.79 & 0.68 & 0.91 \\
Median & 0.79 & 0.66 & 0.90 \\
Mean & 0.78 & 0.64 & 0.89 \\
Minimum & 0.77 & 0.63 & 0.88 \\
$\quad$ Maximum & 0.76 & & \\
\hline NIR = near-infrared, TcPO & \\
\hline
\end{tabular}

(86.5\% of proximal) and NIR laser (81.5\% of proximal). No significance was found for $\mathrm{TcPO}_{2}$ normalized values $(F=1.29, p=0.28)$.

\section{DISCUSSION}

We specifically designed this study to assess LDI as a technology for evaluating PVD and to compare its accuracy with that of $\mathrm{TcPO}_{2}$. Although $\mathrm{TcPO}_{2}$ has been extensively used over the years to estimate viability of ischemic tissue, it is a technique that assesses skin perfusion only indirectly and is prone to complications from limited oxygen diffusion because of local edema and skin thickness [11-13]. Edema is prevalent in PVD complicated by infection, and skin thickness severely limits the usefulness of $\mathrm{TcPO}_{2}$ in the plantar surface of the foot.

We tested LDI and $\mathrm{TcPO}_{2}$ on the same subjects and skin sites by using the local heating required to determine $\mathrm{TcPO}_{2}$ and by measuring the LDI flux within the area over which the $\mathrm{TcPO}_{2}$ was averaged. This design characteristic is particularly valuable for assessing the validity of the correlation study between both methods. $\mathrm{TcPO}_{2}$ and laser Doppler flowmetry measurements of different areas within the same general regions have been previously compared [23-24]. One advantage of LDI over single-contact laser Doppler measurements is the ability to study the local variability of flux within the heated area at two depths within the skin: a superficial region with the red laser and an aggregate of superficial and deeper portions of the skin with the NIR laser [18]. The relative merits of the two types of lasers in evaluating ischemic skin have not been studied before. In addition, we matched the age of the two subject groups (ischemic and control) by design to avoid possible differences due to this variable, although the effect of age on laser Doppler skin perfusion measurements appears to be weak at best [25-26].

The distribution of the regions studied was designed to provide clinically useful information of a possible proximal-to-distal decreasing perfusion gradient that could help decide the suitability of a transtibial amputation. In this sense, our data indicate that only the LDI flux ratio could detect such a gradient in the patients studied who were deemed candidates for transtibial amputation based on the presence of the following signs and symptoms:

- Severely impaired walking ability.

- Pain at rest, exacerbated by elevation of the limb.

- Edema or cellulitis.

- Atrophy of the calf muscles.

- Trophic changes and extremely pale or cyanotic skin with decreased local temperature.

- Absence of pedal pulses.

- Nonhealing ischemic ulcers, osteomyelitis refractory to treatment, nonhealing foot amputation, or gangrene.

Comparison of the average values of $\mathrm{TcPO}_{2}$ obtained in the control group in the present study with those previously reported in the literature for groups of comparable age at leg sites generally agrees with the average values of the three lateral sites (proximal, middle, and distal) in our study (mean $=51.4,95 \%$ confidence interval $=48.4$ 54.3). Smith et al. reported a mean $\mathrm{TcPO}_{2}$ of $59.84 \mathrm{mmHg}$ in the legs of 16 control volunteers [27], Olerud et al. a mean $\mathrm{TcPO}_{2}$ of 54.1 (right leg) and $57.1 \mathrm{mmHg}$ (left leg) in a group of 10 volunteers [28], and Orenstein et al. a mean $\mathrm{TcPO}_{2}$ of $54 \mathrm{mmHg}$ in 8 volunteers older than 40 years [29]. The values in these studies are somewhat higher than ours, probably because of differences in the amount of time the probes were left in place before they 

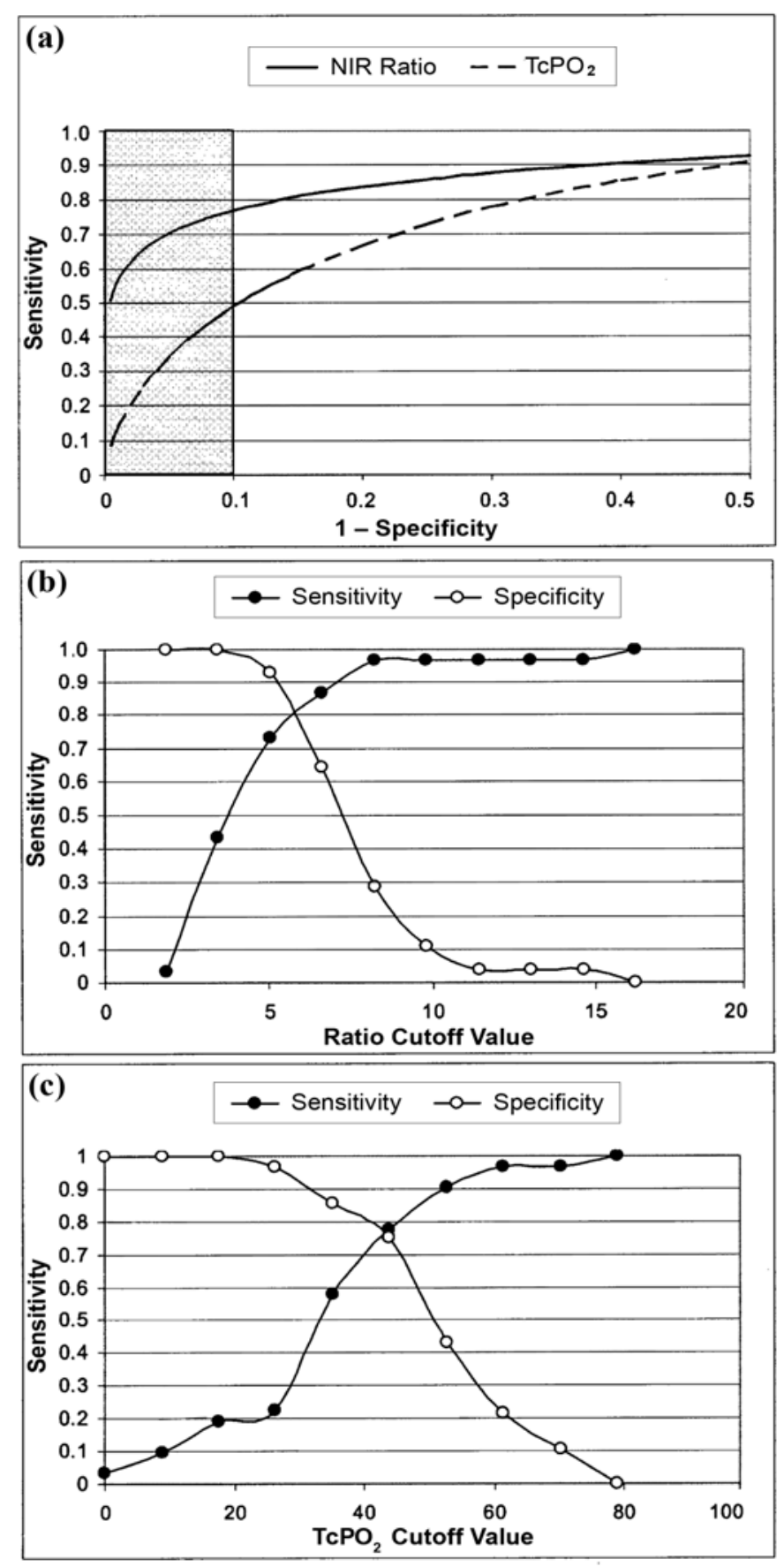

Figure 3.

(a) Receiver operating characteristic (ROC) plots of sensitivity or true positive rate ( $y$-axis) against 1 - specificity or false positive rate $(x$ axis) for laser Doppler imaging (LDI) near-infrared (NIR) laser ratio (solid line) and transcutaneous partial pressure of oxygen $\left(\mathrm{TcPO}_{2}\right)$ (dashed line). Gray shaded area is range of 1 -specificities within which sensitivity was significantly higher for LDI NIR laser ratio than for $\mathrm{TcPO}_{2}$. (b) and (c) show plots of sensitivity (•) and specificity (O) calculated with ROC procedure at select cutoff points of (b) LDI NIR laser ratio and (c) $\mathrm{TcPO}_{2}$. were read. Olerud et al. left the probes in place for $10 \mathrm{~min}-$ utes [28], Smith et al. for 10 to 20 minutes [27], while Orenstein et al. did not give the time [29]. In our case, we waited until the decreasing trend of $\mathrm{TcPO}_{2}$ reached a steady state (unchanged values over 4 minutes) - an average 28.9 minutes with a range of 9 to 49 minutes for the control group. Unfortunately, most of the studies of Tc gases reviewed failed to either specify the criterion for taking a measurement (time or steady-state) or provide a consistent procedure. Theoretically, a steady state should be observed before taking the measurement [8], and in our experience, the time to steady state may differ appreciably between individuals. The time to reach a steady state in ischemic subjects is certainly longer than in nonischemic control subjects. Thus, a fixed time interval for routine measurement of $\mathrm{TcPO}_{2}$ is not advisable. In a study of younger subjects (mean age 45 years), mean values ranging from 69 to $74 \mathrm{mmHg} \mathrm{TcPO}_{2}$ were reported at leg sites $10 \mathrm{~cm}$ below the knee [30]. In this case, age may explain the higher values since it has been found to negatively correlate with $\mathrm{TcPO}_{2}$ [31]. The same finding may apply to other studies of younger populations [32-33].

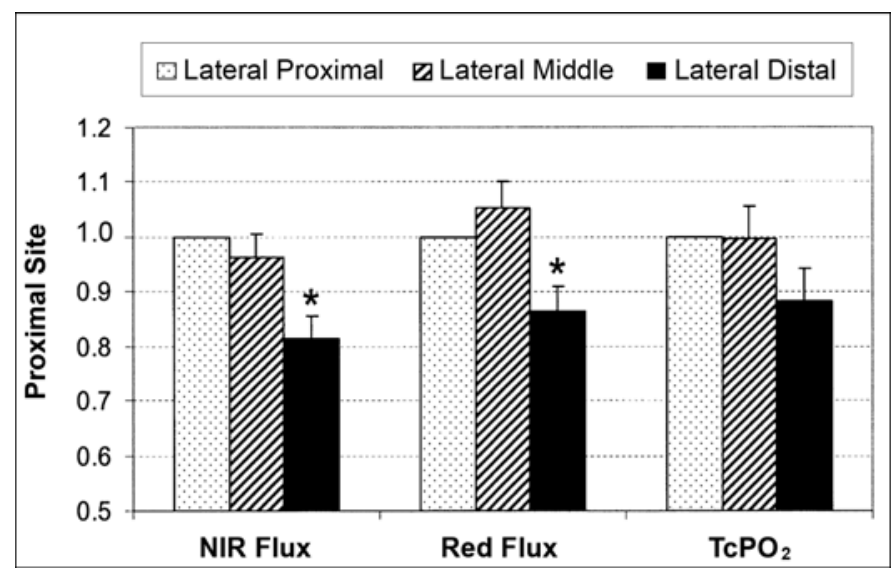

Figure 4.

Laser Doppler imaging (LDI) flux measured with red and nearinfrared (NIR) lasers and $\mathrm{TcPO}_{2}$ from lateral-middle and -distal sites from ischemic group were normalized by dividing them by the respective values of lateral-proximal site. Bars are mean and error bars are standard error. Analysis of variance (ANOVA) indicated significance for red laser LDI flux $(F=4.55, p=0.01)$ and NIR laser LDI flux ( $F=5.99, p=0.004$ ), and multiple comparisons (TukeyKramer test, $p<0.05$ ) showed that lateral distal LDI flux was significantly lower than lateral middle and proximal sites with both laser types $(*)$. No significance was found for $\mathrm{TcPO}_{2}$ normalized values ANOVA $(F=1.29, p=0.28)$. 
The ROC data indicated that although the accuracy of $\mathrm{TcPO}_{2}$ and LDI flux ratio at discriminating between the two subject groups did not statistically differ over the full range of specificity values (estimated by the area under the curve of the ROC plot) at the high specificity $(\geq 0.9)$ range, LDI flux ratio was significantly more sensitive that $\mathrm{TcPO}_{2}$. This is clinically significant because assurance of specificity (the ability to identify absence of critical ischemia when it does not exist) is an important characteristic of a method in the decision to amputate a limb.

Although these methods must have the capability to discriminate between the nonischemic and ischemic populations without any other information, an ancillary question is whether they can detect differences between distal leg sites, which can be expected to have worse perfusion than proximal leg sites in these ischemic subjects. The results indicated that the NIR laser ratio was superior than $\mathrm{TcPO}_{2}$ in this respect.

The lack of correlation between $\mathrm{TcPO}_{2}$ and LDI flux in normal control subjects is not surprising. Theoretical modeling of oxygen diffusion through the skin has indicated that within a wide range of high perfusion values, $\mathrm{PO}_{2}$ at the site of detection (skin surface) approximates $\mathrm{PO}_{2}$ at the source (blood vessels). However, as the local blood flow parameter decreases in value in the model, the $\mathrm{PO}_{2}$ at the electrode-covered skin surface decreases relative to the source [8]. Steinacker et al. has demonstrated this phenomenon through experiments [34]. Conceivably, the levels of local blood flow in nonischemic subjects are within the range where little effect of perfusion on probe $\mathrm{PO}_{2}$ can be expected. In other words, local blood flow may not be the limiting factor for skin surface $\mathrm{PO}_{2}$ under the probe in normal skin, but it may be so in ischemic skin. Thus, $\mathrm{TcPO}_{2}$ may be considered an index of skin perfusion only in conditions of reduced blood flow.

$\mathrm{TcPCO}_{2}$ proved to be insensitive to changes in local perfusion and of no value at discriminating between the two subject groups. The greater diffusivity of $\mathrm{CO}_{2}$ could be invoked as a possible cause for a better agreement between blood and skin surface $\mathrm{PCO}_{2}$ than $\mathrm{PO}_{2}$ at the measuring probes.

The differences observed between laser types have important implications. At all sites and in both subject groups, the NIR laser showed considerably less variability than the red laser. Several factors may have caused the greater variability and maximum values observed with the red laser. The NIR laser appears to detect events at greater depths within the skin [18] and perhaps even in the subdermal region, where perfusion could be more homogeneous than in more superficial layers with abundance of sweat glands, one of the main determinants of skin blood flow responses. On the other hand, shifts in reflected light frequency due to optical characteristics at the skin surface could have a greater contribution in the case of red light. Whatever the reason, the NIR laser appears to have an advantage over the red laser for estimating skin perfusion.

\section{CONCLUSIONS}

This study has determined that the average, SD, maximum, minimum, and median values of LDI flux within heated skin areas are decreased in all leg sites tested in ischemic subjects when compared with nonischemic agematched control subjects. In contrast, the flux of nonheated areas failed to discriminate between the two subject groups. Similar results were obtained with NIR and red laser flux measurements, but NIR laser measurements of flux may have an advantage over red laser measurements since they detect less variability (lower SD) within heated areas in both subject groups.

The flux ratio of the heated to nonheated areas showed better sensitivity than $\mathrm{TcPO}_{2}$ when specificity was 90 percent or higher. Only flux of heated areas could identify a proximal to a distal gradient of skin perfusion present in ischemic legs.

\section{ACKNOWLEDGMENTS}

Jessica Johnson, PT, is now with the Western University of Health Sciences, Pomona, California.

This material was based on work supported by VA Rehabilitation Research and Development awards (A2196PA and A2860R) and a Senior Research Career Scientist award (B2541SA) to Dr. Oscar Scremin.

The authors have declared that no competing interests exist.

\section{REFERENCES}

1. Feinglass J, Kaushik S, Handel D, Kosifas A, Martin GJ, Pearce WH. Peripheral bypass surgery and amputation: 
Northern Illinois demographics, 1993 to 1997. Arch Surg. 2000;135(1):75-80. [PMID: 10636352]

2. Dillingham TR, Pezzin LE, MacKenzie EJ. Limb amputation and limb deficiency: epidemiology and recent trends in the United States. South Med J. 2002;95(8):875-83. [PMID: 12190225]

3. Dillingham TR, Pezzin LE, Shore AD. Reamputation, mortality, and health care costs among persons with dysvascular lower-limb amputations. Arch Phys Med Rehabil. 2005; 86(3):480-86. [PMID: 15759232]

4. Dormandy J, Heeck L, Vig S. Major amputations: clinical patterns and predictors. Semin Vasc Surg. 1999;12(2):154-61. [PMID: 10777243]

5. Fletcher DD, Andrews KL, Butters MA, Jacobsen SJ, Rowland CM, Hallett JW Jr. Rehabilitation of the geriatric vascular amputee patient: a population-based study. Arch Phys Med Rehabil. 2001;82(6):776-79. [PMID: 11387582]

6. Management of peripheral arterial disease (PAD). TransAtlantic Inter-Society Consensus (TASC). Section D: chronic critical limb ischaemia. Eur J Vasc Endovasc Surg. 2000;19 Suppl A:S144-243. [PMID: 10957907]

7. Huch R, Huch A, Lubbers DW. Transcutaneous measurement of blood $\mathrm{Po}_{2}\left(\mathrm{tcPo}_{2}\right)$ - Method and application in perinatal medicine. J Perinat Med. 1973;1(3):183-91. [PMID: 4806572]

8. Huch R, Huch A, Lubbers DW. Transcutaneous $\mathrm{PO}_{2}$. New York (NY): Thieme-Stratton Inc; 1981.

9. Burgess EM, Matsen FA 3rd, Wyss CR, Simmons CW. Segmental transcutaneous measurements of $\mathrm{PO}_{2}$ in patients requiring below-the-knee amputation for peripheral vascular insufficiency. J Bone Joint Surg Am. 1982;64(3):378-82. [PMID: 7061555]

10. Franzeck UK, Talke P, Bernstein EF, Golbranson FL, Fronek A. Transcutaneous $\mathrm{PO}_{2}$ measurements in health and peripheral arterial occlusive disease. Surgery. 1982;91(2):156-63. [PMID: 7058493]

11. Boyko EJ, Ahroni JH, Stensel VL, Smith DG, Davignon DR, Pecoraro RE. Predictors of transcutaneous oxygen tension in the lower limbs of diabetic subjects. Diabet Med. 1996;13(6):549-54. [PMID: 8799659]

12. Southwood WF. The thickness of the skin. Plast Reconstr Surg. 1955;15(5):423-29. [PMID: 14384521]

13. Falstie-Jensen N, Spaun E, Brochner-Mortensen J, FalstieJensen $\mathrm{S}$. The influence of epidermal thickness on transcutaneous oxygen pressure measurements in normal persons. Scand J Clin Lab Invest. 1988;48(6):519-23. PMID: 3217755

14. Scheffler A, Rieger H. A comparative analysis of transcutaneous oximetry $\left(\mathrm{tcPO}_{2}\right)$ during oxygen inhalation and leg dependency in severe peripheral arterial occlusive disease. J Vasc Surg. 1992;16(2):218-24. [PMID: 1495145$]$

15. Lantsberg L, Goldman M. Laser Doppler flowmetry, transcutaneous oxygen tension measurements and Doppler pres- sure compared in patients undergoing amputation. Eur $\mathrm{J}$ Vasc Surg. 1991;5(2):195-97. [PMID: 2037090]

16. Karanfilian RG, Lynch TG, Zirul VT, Padberg FT, Jamil Z, Hobson RW 2nd. The value of laser Doppler velocimetry and transcutaneous oxygen tension determination in predicting healing of ischemic forefoot ulcerations and amputations in diabetic and nondiabetic patients. J Vasc Surg. 1986;4(5):511-16. [PMID: 2945936]

17. Fairs SL, Ham RO, Conway BA, Roberts VC. Limb perfusion in the lower limb amputee-a comparative study using a laser Doppler flowmeter and a transcutaneous oxygen electrode. Prosthet Orthot Int. 1987;11(2):80-84. [PMID: 2958776]

18. Abbot NC, Ferrell WR, Lockhart JC, Lowe JG. Laser Doppler perfusion imaging of skin blood flow using red and nearinfrared sources. J Invest Dermatol. 1996;107(6):882-86. [PMID: 8941679]

19. Essex TJ, Byrne PO. A laser Doppler scanner for imaging blood flow in skin. J Biomed Eng. 1991;13(3):189-94. [PMID: 1870327]

20. Stucker M, Heese A, Hoffmann K, Rochling A, Altmeyer P. Precision of laser Doppler scanning in clinical use. Clin Exp Dermatol. 1995;20(5):371-76. [PMID: 8593712]

21. Kubli S, Waeber B, Dalle-Ave A, Feihl F. Reproducibility of laser Doppler imaging of skin blood flow as a tool to assess endothelial function. J Cardiovasc Pharmacol. 2000; 36(5):640-48. [PMID: 11065225]

22. Park SH, Goo JM, Jo CH. Receiver operating characteristic (ROC) curve: practical review for radiologists. Korean J Radiol. 2004;5(1):11-18. PMID: 15064554

23. Caspary L, Creutzig A, Alexander K. Comparison of Laser-Doppler-Flux and tc $\mathrm{PO}_{2}$ in healthy probands and patients with arterial ischemia. Adv Exp Med Biol. 1987; 220:235-40. [PMID: 2960138]

24. Allen PI, Goldman M. Skin blood flow: a comparison of transcutaneous oximetry and laser Doppler flowmetry. Eur J Vasc Surg. 1987;1(5):315-18. [PMID: 2971577]

25. Evans E, Rendell M, Bartek J, Connor S, Bamisedun O, Dougan D, Giitter M. Thermally-induced cutaneous vasodilatation in aging. J Gerontol. 1993;48(2):M53-57. [PMID: 8473694]

26. Minson CT, Holowatz LA, Wong BJ, Kenney WL, Wilkins BW. Decreased nitric oxide- and axon reflex-mediated cutaneous vasodilation with age during local heating. J Appl Physiol. 2002;93(5):1644-49. [PMID: 12381749]

27. Smith DG, Boyko EJ, Ahroni JH, Stensel VL, Davignon DR, Pecoraro RE. Paradoxical transcutaneous oxygen response to cutaneous warming on the plantar foot surface: a caution for interpretation of plantar foot $\mathrm{TcPO}_{2}$ measurements. Foot Ankle Int. 1995;16(12):787-91.

[PMID: 8749350] 
28. Olerud JE, Pecoraro RE, Burgess EM, McKnight B, Wyss CR, Reiber GE, Matsen FA 3rd. Reliability of transcutaneous oxygen tension $\left(\mathrm{TcPO}_{2}\right)$ measurements in elderly normal subjects. Scand J Clin Lab Invest. 1987;47(6):535-41. [PMID: 3672026]

29. Orenstein A, Mazkereth R, Tsur H. Mapping of the human body skin with the transcutaneous oxygen pressure method. Ann Plast Surg. 1988;20(5):419-25. [PMID: 3377419]

30. Dowd GS, Linge K, Bentley G. Measurement of transcutaneous oxygen pressure in normal and ischaemic skin. J Bone Joint Surg Br. 1983;65(1):79-83. [PMID: 6822606]

31. Uccioli L, Monticone G, Russo F, Mormile F, Durola L, Mennuni G, Bergamo F, Menzinger G. Autonomic neuropathy and transcutaneous oxymetry in diabetic lower extremities. Diabetologia. 1994;37(10):1051-55. [PMID: 7851684]
32. Coleman LS, Dowd GS, Bentley G. Reproducibility of $\mathrm{tcPO}_{2}$ measurements in normal volunteers. Clin Phys Physiol Meas. 1986;7(3):259-63. [PMID: 3769415$]$

33. Wyss CR, Matsen FA 3rd, King RV, Simmons CW, Burgess EM. Dependence of transcutaneous oxygen tension on local arteriovenous pressure gradient in normal subjects. Clin Sci (Lond). 1981;60(5):499-506. [PMID: 7249535]

34. Steinacker JM, Spittelmeister W, Wodick R. Examinations on the blood flow dependence of $\mathrm{tcPO}_{2}$ using the model of the "circulatory hyperbola." Adv Exp Med Biol. 1987; 220:263-68. [PMID: 2960140]

Submitted for publication February 15, 2006. Accepted in revised form August 3, 2006. 